\title{
ARD
}

\section{Structural and inflammatory sonographic findings in erosive and non-erosive osteoarthritis of the interphalangeal finger joints}

Ruth Wittoek, Philippe Carron and Gust Verbruggen

Ann Rheum Dis 2010 69: 2173-2176 originally published online August 6, 2010

doi: $10.1136 /$ ard.2010.128504

Updated information and services can be found at:

http://ard.bmj.com/content/69/12/2173.full.html

These include:

Data Supplement

"Web Only Data"

http://ard.bmj.com/content/suppl/2010/06/30/ard.2010.128504.DC1.html

References This article cites 18 articles, 6 of which can be accessed free at: http://ard.bmj.com/content/69/12/2173.full.html\#ref-list-1

Email alerting service

Receive free email alerts when new articles cite this article. Sign up in the box at the top right corner of the online article.

Notes

To request permissions go to:

http://group.bmj.com/group/rights-licensing/permissions

To order reprints go to:

http://journals.bmj.com/cgi/reprintform

To subscribe to BMJ go to:

http://journals.bmj.com/cgi/ep 


\title{
Structural and inflammatory sonographic findings in erosive and non-erosive osteoarthritis of the interphalangeal finger joints
}

\author{
Ruth Wittoek, Philippe Carron, Gust Verbruggen
}

- Additional supplementary data are published online only. To view these files please visit the journal online (http://ard. bmj.com).

Department of Rheumatology, University Hospital Gent, Gent, Belgium

\section{Correspondence to}

Dr Ruth Wittoek, Department of Rheumatology, University Hospital Gent, 0K12-IB, De Pintelaan 185, B-9000 Gent, Belgium;

ruth.wittoek@ugent.be

Accepted 25 June 2010

Published Online First 6 August 2010

\begin{abstract}
Objective The objectives were: (1) to determine if ultrasound (US) can detect more erosions in erosive osteoarthritis (EOA) of the interphalangeal (IP) joints than conventional radiography (CR); and (2) to explore the frequency of structural and inflammatory findings in EOA and non-EOA.
\end{abstract}

Methods Structural changes and the anatomical phase were scored on CR in IP joints of 31 patients with EOA and 7 patients with non-EOA. Structural and inflammatory changes were scored by US. The frequency of sonographic findings was compared between the anatomical phases and between EOA and non-EOA by generalised estimation equation (GEE) modelling. Results US detected 68 of 72 (94.4\%) erosions seen on CR. US detected 45 additional erosive joints in EOA. The frequency of joint effusion and power Doppler signal was similar in EOA compared to non-EOA ( $p=0.91$ and $p=0.68$, respectively). Statistically significantly more synovitis was present in full erosive phase compared to non-erosive phases in EOA $(p=0.04)$. No differences in inflammatory findings were found between non-erosive phases in EOA and non-EOA.

Conclusion US is capable of detecting erosions in radiographic non-erosive phases. The highest frequency of synovitis is present in erosive joints but inflammatory findings are common in all anatomical phases of EOA and non-EOA.

\section{INTRODUCTION}

Erosive osteoarthritis (EOA) of the interphalangeal (IP) joints is an important subtype of hand osteoarthritis (OA). It is characterised by a rather aggressive clinical course and causes pain and limitation of function. ${ }^{12}$ Controversy remains in the literature as to whether EOA is a separate disease entity. ${ }^{13} 4$ As inflammatory episodes characterise the onset of this disease, EOA is sometimes called inflammatory $O A^{\prime} .^{5} 6$

The diagnosis is based upon conventional radiography (CR) that shows typical central erosions and collapse of the subchondral bone. ${ }^{1478}$ Several radiographic phases are being recognised in EOA. ${ }^{4}$ Unfortunately, the radiographic appearance of erosions shows a delay with respect to the clinical presentation.

As in rheumatoid and psoriatic arthritis, ultrasound (US) may serve as a tool to identify the erosions before CR does. ${ }^{9}{ }^{10}$ A recent study reported the presence of many inflammatory sonographic features in EOA and a high percentage of power Doppler (PD) signal, which is consistent with the inflammatory nature of the disease. ${ }^{11}$
The aims of this study were twofold: (1) to determine if US can detect more erosions in EOA than $\mathrm{CR}$ in different radiographic anatomical phases, and if erosions are present in radiographic nonerosive hand $\mathrm{OA}$; and (2) to explore the frequency of structural and inflammatory sonographic findings in EOA and non-EOA.

\section{PATIENTS AND METHODS}

\section{Patients}

All 18 IP finger joints of 38 patients were examined by US and CR. All patients fulfilled the American College of Rheumatology criteria for hand OA. ${ }^{12}$ A total of 31 patients were diagnosed as having EOA (26 women) with a mean age of 60.7 years $(\mathrm{SD} \pm 6.7)$ and mean disease duration of 10.3 years $(\mathrm{SD} \pm 4.9)$. Diagnosis of EOA was based upon presence of radiographic erosions in at least one joint. Seven consecutive patients with non-EOA (all women) with a mean age of 63.7 years $(\mathrm{SD} \pm 4.3)$ and mean disease duration of 10.6 years $(\mathrm{SD} \pm 4.0)$ were examined. The study was approved by the local ethics committee and informed consent was obtained from each participant.

\section{Imaging techniques}

Posteroanterior CR and US were performed on the same day. US was performed using a MyLab 25 (Esaote, Genova, Italy) machine with a 10-18 MHz linear array transducer by a rheumatologist, experienced in musculoskeletal US (RW) and blinded for diagnosis. The PD was set to a frequency of 8.3 $\mathrm{MHz}$, and a pulse repetition frequency of $500 \mathrm{MHz}$. Longitudinal and transverse scans were performed on dorsal and volar sides, sequentially with the finger extended and in maximal flexion, allowing maximal visualisation of the joint surface.

\section{Assessments}

All sonographic images were scored by RW for the presence of structural lesions, that is, erosions (defined as a cortical break, confirmed in two perpendicular planes) and osteophytes or bone proliferations, and inflammatory signs (joint effusion, greyscale synovitis and intracapsular increased PD signals), as defined by the criteria of Outcome Measures in Rheumatoid Arthritis Clinical Trials (OMERACT; figure 1). ${ }^{13}$ A second experienced sonographer (PC), blinded for diagnosis, repeated the scoring of the stored US images in 10 patients.

All joints of patients with EOA were classified independently by GV on CR according to the anatomical phase scoring system, including the 'N' (normal), 'S' (stationary, showing minimal 

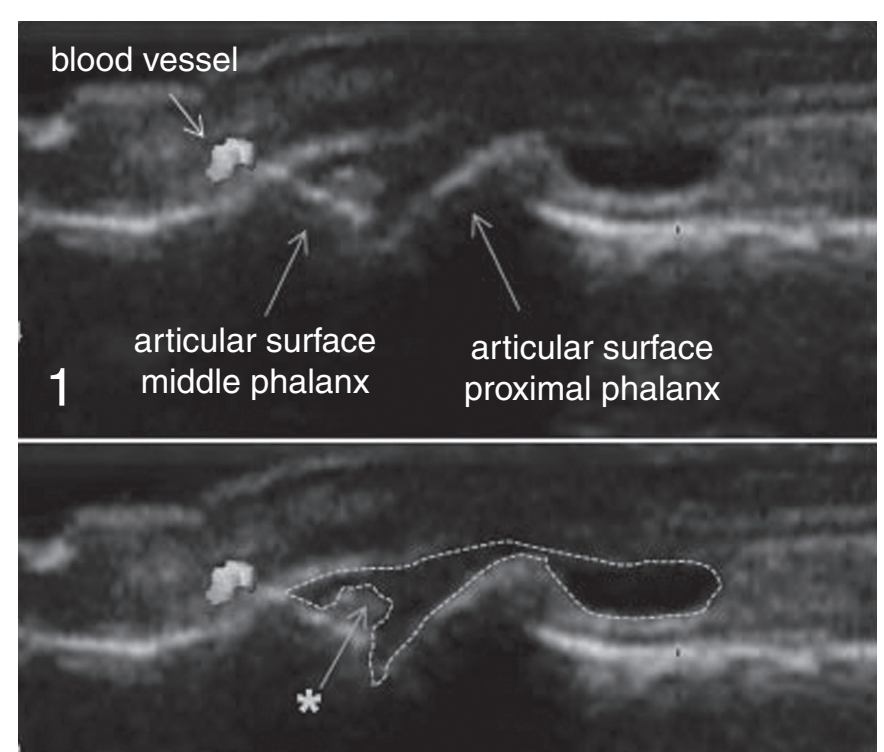

2

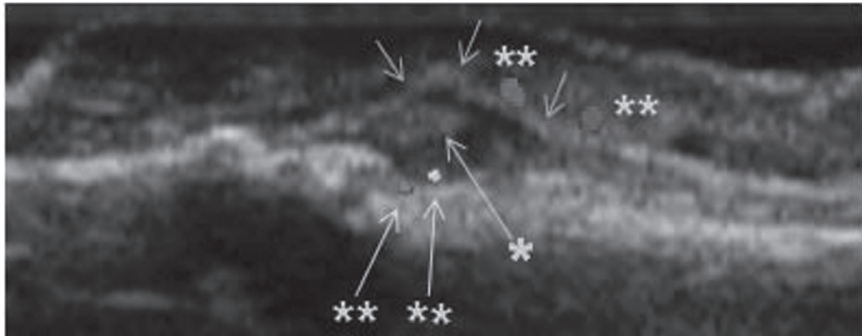

3
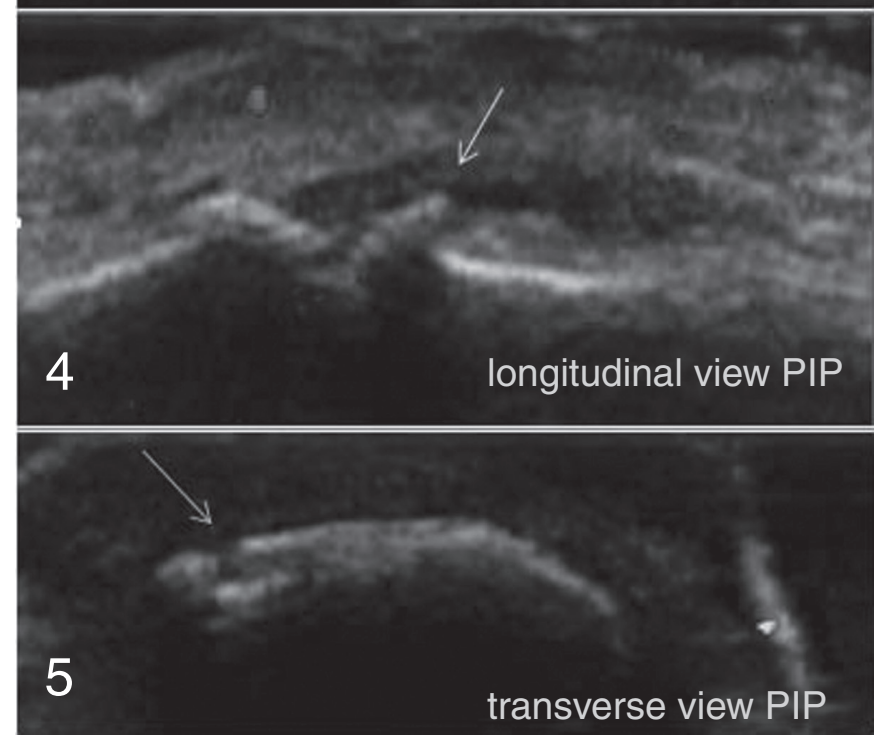

Figure 1 Sonographic images of interphalangeal (IP) finger joints. 1-4: longitudinal scan of a proximal IP joint; 2: the selected area of anechoic signal represents effusion of the joint, asterisk: greyscale synovitis; 3: arrows aligning the anterior joint capsule, asterisk: greyscale synovitis, double asterisk: intracapsular and extracapsular power Doppler signals; 4: arrow showing a bony proliferation or osteophyte; 5 : transverse scan of a proximal IP joint, arrow: showing an irregularity of the bony surface representing a bone erosion (confirmed in longitudinal view). degenerative signs), 'J' (complete loss of joint space), 'E', (erosive) and ' $R$ ' phase (remodelling) (figure 2). ${ }^{4}$ Joints of patients with non-erosive OA were scored as normal or abnormal (ie, showing radiographic signs of degenerative disease).

\section{Statistical analysis}

Generalised estimation equation (GEE) modelling was used to compare frequencies of sonographic findings between different radiographic phases and between EOA and non-EOA with correction for subject level $(\alpha=0.05)$. OR and 95\% CI were calculated with the normal and erosive phase as referent. Inter-reader reliability (RW and PC, measured by unweighted $\kappa$ statistics) was found to be excellent for all variables $(\kappa=0.91$ for erosions, $\kappa=0.98$ for osteophytes, $\kappa=0.98$ for effusion, $\kappa=0.99$ for greyscale synovitis and $\kappa=0.94$ for $\mathrm{PD}$ signal).

\section{RESULTS}

\section{Structural findings}

The distributions of radiographic anatomic phases of all 558 joints in EOA and of normal or affected joints in 126 joints in non-EOA are shown in table 1.

US detected 68 of $72(94.4 \%)$ radiographic erosive joints. Moreover, 45 additional erosive joints were identified by US $(p=0.01)$ (11 in 'N', 15 in 'S', 4 in 'J' and 15 in 'R' phase). US missed erosions in four joints compared to CR. No statistical significant differences were found between the frequency of erosions in ' $\mathrm{N}$ ' compared to ' $\mathrm{S}$ ' and 'J' phases ( $\mathrm{p}=0.11$ and $\mathrm{p}=0.98$, respectively). Comparisons of frequencies of erosions between all phases in EOA are shown in the supplementary material.

In the non-EOA, US detected erosions not visible on CR in 6 of $126(4.8 \%)$ joints. No significant differences were found between the normal and affected joints in non-EOA $(p=0.21)$ (supplementary material).

Osteophytes were detected by US in 340 of 558 (60.9\%) and 79 of $126(62.7 \%)$ joints in EOA and non-EOA, respectively. CR was found less sensitive ( $45.4 \%$ in EOA ( $p=0.001)$ and $43.3 \%$ in non-EOA $(p=0.007))$. US detected 244 of 253 and 48 of 55 radiographic osteophytes in EOA and non-EOA, respectively. The frequency of bony proliferations was highest in the ' $R$ ' joints $(95.8 \%)$.

\section{Inflammatory findings}

Greyscale synovitis was seen in 92 of $558(16.5 \%)$ joints in EOA and in 16 of 126 joints $(12.7 \%)$ in non-EOA ( $p=0.076)$. Joint effusion was present in 254 of $558(45.5 \%)$ joints in EOA and in 61 of $126(48.4 \%)$ in non-EOA ( $\mathrm{p}=0.91)$. Only small percentages of PD signals were found: in 12 of $558(2.2 \%)$ joints in EOA and in

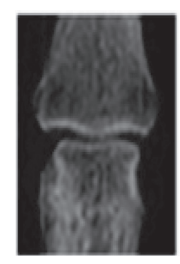

$\mathrm{N}$

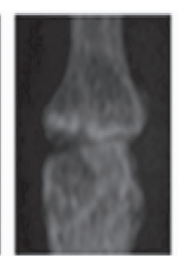

S

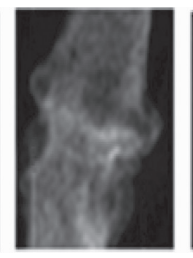

$J$

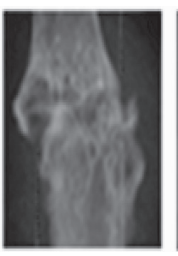

E

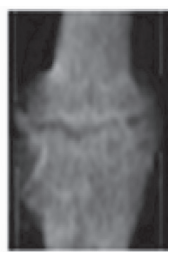

R
Figure 2 Anatomical phases described on radiology. $\mathrm{E}$, erosive phase; $\mathrm{J}$, complete loss of joint space; N, normal joint; $\mathrm{R}$, repair/remodelling; $\mathrm{S}$, stationary joint with classic osteoarthritis features. 
Table 1 Number of joints (\%) and number of patients across radiographic phases with sonographic features in EOA ( $n=558$ joints; 31 patients) and non-EOA ( $n=126,7$ patients)

\begin{tabular}{|c|c|c|c|c|c|}
\hline Anatomic phase* & Erosion (\%) & Osteophyte (\%) & Joint effusion (\%) & Synovitis (\%) & PD signal (\%) \\
\hline \multicolumn{6}{|l|}{ EOA } \\
\hline$N(n=192)$ & $11(5.7) / 7$ & $79(41.1) / 23$ & $69(35.9) / 23$ & $31(16.1) / 17$ & $0(0) / 0$ \\
\hline$S(n=168)$ & $15(8.9) / 12$ & $100(59.5) / 27$ & $91(54.2) / 28$ & $19(11.3) / 12$ & $6(3.6) / 5$ \\
\hline$J(n=55)$ & $4(7.3) / 4$ & $32(58.2) / 19$ & $22(40.0) / 17$ & $6(10.9) / 6$ & $1(1.8) / 1$ \\
\hline$E(n=72)$ & $68(94.4) / 28$ & $61(84.7) / 27$ & $43(59.7) / 21$ & $19(26.4) / 11$ & $4(5.6) / 2$ \\
\hline$R(n=71)$ & $15(21.1) / 12$ & $68(95.8) / 30$ & $29(40.8) / 18$ & $17(23.9) / 11$ & $1(1.4) / 1$ \\
\hline \multicolumn{6}{|l|}{ Non-EOA } \\
\hline$N(n=62)$ & $2(3.2) / 2$ & $28(45.2) / 7$ & $28(45.2) / 6$ & $8(12.9) / 3$ & $1(1.6) / 1$ \\
\hline$A(n=64)$ & $4(6.2) / 3$ & $51(79.7) / 7$ & $33(51.6) / 7$ & $8(12.5) / 5$ & $0(0) / 0$ \\
\hline
\end{tabular}

${ }^{*}$ In EOA: all joints are characterised according to the anatomical scoring system. ${ }^{4}$ In non-EOA: all joints are scored as being normal (N) or affected by radiographic signs of degenerative disease (A).

$E$, erosive phase; EOA, erosive osteoarthritis; J, complete loss of joint space; N, normal joint; PD, power Doppler; $R$, repair/ remodelling; S, stationary joint with classic osteoarthritis features.

only 1 joint of $126(0.8 \%)$ in non-EOA ( $p=0.68)$. Again, no statistically significant differences in inflammatory findings were found between subgroups of EOA and non-EOA (all p $>0.05$, see supplementary material).

In EOA, the frequency of effusion, synovitis and PD signal was highest in the ' $E$ ' joints $(59.7 \%, 26.4 \%$ and $5.6 \%$, respectively). However, inflammatory features were present in slightly lower percentages in the radiographic non-erosive and ' $R$ ' phases (table 1). With 'E' phase as referent, statistical significance was reached for synovitis in all phases in EOA, except in ' $R$ ' phase (see supplementary material).

\section{DISCUSSION}

This study showed that US is more sensitive in detecting erosions compared to CR. Moreover, erosions can be seen by US in the non-erosive radiographic phases of erosive hand $\mathrm{OA}$ (ie, in joints in ' $N$ ', 'S', 'J' and 'R' phases). Additionally, high frequencies of inflammatory changes were seen in erosive as well as in non-erosive joints.

The higher sensitivity of US in detecting erosions has previously been reported in a previous study on $\mathrm{OA}^{11}$ and is in line with other disease groups, such as rheumatoid arthritis and psoriatic arthritis. ${ }^{3}{ }^{4}$ Erosions were missed using US in only four radiographic erosive joints, probably due to interposition of osteophytes, known to disturb the acoustic window. In the control group of patients who were non-EOA, we detected erosions in only six joints that appeared non-erosive on CR. These results are in line with the excellent specificity reported by Iagnocco et al. ${ }^{14}$

In EOA, US could contribute to an earlier identification of erosive joints. To confirm if these sonographic erosions will become 'true' radiographic erosions, a longitudinal study is required and other imaging constructs should be used.

Concerning the detection of osteophytes, our data are in line with previous reports showing US to be more sensitive than CR in hand OA. ${ }^{11} 1516$

We also investigated the presence of inflammatory sonographic features in EOA and non-EOA. A trend towards more inflammatory signs in full erosive phase is detected. However, the frequency of effusion seems to be high in all anatomic phases. Greyscale synovitis was seen almost twice as often in 'E' and 'R' phases compared to 'N', 'S' and 'J' phases. A similar frequency of synovitis has been reported recently. ${ }^{11}$ The synovitis observed in the remodelled phase might represent signs of residual inflammation. Our data showed a considerably higher frequency of effusion (59.7\%) compared to this latter study
$(18 \%)$. However, frequencies up to $20 \%$ have been reported in normal proximal IP joints. ${ }^{17}$ Additionally, we could not confirm the high percentages of $\mathrm{PD}$ signal reported by Vlychou et al $(22.4 \%)$. However, our data $(5.6 \%)$ are in line with a study in patients with symptomatic hand OA $(6.8 \%) .{ }^{18}$ In the present study, a similar frequency of inflammatory signs was seen in the control group of non-EOA compared to non-erosive joints in EOA. The role of inflammation in the pathogenesis of EOA is not yet clear.

There are some limitations to this study. Firstly, the number of patients in the control group was rather small. Secondly, no longitudinal follow-up has been performed. And thirdly, no other imaging constructs were present to confirm the sonographic features.

In conclusion, US can detect erosions not seen by CR in erosive and non-erosive IP OA and may be supplementary to $\mathrm{CR}$ in establishing erosive features in radiographic non-erosive hand OA. Inflammatory features are slightly more prevalent in the full erosive phase but they are not specific for erosive disease.

Funding RW is a research fellow supported by a Ghent University Coordinated Research Initiative (GOA) grant (BOF07/GOA/002).

Competing interests None.

Ethics approval This study was conducted with the approval of the University Hospital Gent, Belgium.

Provenance and peer review Not commissioned; externally peer reviewed.

\section{REFERENCES}

1. Peter JB, Pearson CM, Marmor L. Erosive osteoarthritis of the hands. Arthritis Rheum 1966;9:365-88.

2. Punzi L, Ramonda R, Sfriso P. Erosive osteoarthritis. Best Pract Res Clin Rheumatol 2004;18:739-58.

3. Cobby M, Cushnaghan J, Creamer P, et al. Erosive osteoarthritis: is it a separate disease entity? Clin Radiol 1990;42:258-63.

4. Verbruggen G, Veys EM. Numerical scoring systems for the anatomic evolution of osteoarthritis of the finger joints. Arthritis Rheum 1996;39:308-20.

5. Ehrlich GE. Inflammatory osteoarthritis. I. The clinical syndrome. J Chronic Dis 1972;25:317-28

6. Crain DC. Interphalangeal osteoarthritis. JAMA 1961;175:1049-53.

7. Stecher RM, Hauser $\mathrm{H}$. Heberden's nodes; the roentgenological and clinical appearance of degenerative joint disease of the fingers. Am J Roentgenol Radium Ther 1948;59:326-37.

8. Verbruggen G, Wittoek R, Vander Cruyssen B, et al. Morbid anatomy of 'erosive osteoarthritis' of the interphalangeal finger joints: an optimised scoring system to monitor disease progression in affected joints. Ann Rheum Dis 2010;69:862-7.

9. Wiell C, Szkudlarek M, Hasselquist M, et al. Ultrasonography, magnetic resonance imaging, radiography, and clinical assessment of inflammatory and destructive changes in fingers and toes of patients with psoriatic arthritis. Arthritis Res Ther 2007;9:R119. 
10. Wakefield RJ, Gibbon WW, Conaghan PG, et al. The value of sonography in the detection of bone erosions in patients with rheumatoid arthritis: a comparison with conventional radiography. Arthritis Rheum 2000;43:2762-70.

11. Vlychou M, Koutroumpas A, Malizos K, et al. Ultrasonographic evidence of inflammation is frequent in hands of patients with erosive osteoarthritis. Osteoarthr Cartil 2009;17:1283-7

12. Altman R, Alarcón G, Appelrouth D, et al. The American College of Rheumatology criteria for the classification and reporting of osteoarthritis of the hand. Arthritis Rheum 1990;33:1601-10.

13. Wakefield RJ, Balint PV, Szkudlarek M, et al. Musculoskeletal ultrasound including definitions for ultrasonographic pathology. J Rheumatol 2005;32:2485-7.

14. Iagnocco A, Filippucci E, Ossandon A, et al. High resolution ultrasonography in detection of bone erosions in patients with hand osteoarthritis. J Rheumatol 2005;32:2381-3.
15. Keen HI, Wakefield RJ, Grainger AJ, et al. Can ultrasonography improve on radiographic assessment in osteoarthritis of the hands? A comparison between radiographic and ultrasonographic detected pathology. Ann Rheum Dis 2008;67:1116-20.

16. Keen HI, Lavie F, Wakefield RJ, et al. The development of a preliminary ultrasonographic scoring system for features of hand osteoarthritis. Ann Rheum Dis 2008:67:651-5

17. Rosenberg C, Arrestier S, Etchepare F, et al. High frequency of ultrasonographic effusion in interphalangeal joints of healthy subjects: a descriptive study. Joint Bone Spine 2009;76:265-7.

18. Keen HI, Wakefield RJ, Grainger AJ, et al. An ultrasonographic study of osteoarthritis of the hand: synovitis and its relationship to structural pathology and symptoms. Arthritis Rheum 2008;59:1756-63. 